ISSN: $2146-3042$

DOI: $10.25095 /$ mufad.905195

\title{
Muhasebe Eğitiminde Sistem Düşüncesi ve Sistem Dinamiği Yaklaşımının Kullanımı: Finansal Muhasebe Dersleri için Bir Model Önerisi *
}

\author{
Melek AKGÜN** \\ Merve KIYMAZ KIVRAKLAR ${ }^{* * *}$
}

ÖZET

Muhasebe eğitiminde kullanılan öğretim yöntem ve tekniklerinin çă̆ın gereksinimlerine uygun olarak güncellenmesine olan ihtiyaç giderek artmaktadır. Ancak literatür incelendiğinde muhasebe eğitiminde kullanımı önerilen ögretim yöntemlerinin, bilgisayar kullanımı, PowerPoint kullanımı, vaka analizi ve muhasebe paket programları ile sınırlı kaldı̆̆ görülmektedir. Bu yöntemlerden farklı olarak muhasebe derslerinin ögretilmesinde sistem düşüncesi ve sistem dinamikleri yaklaşımı yeni bir öğretim yöntemi olarak kullanılabilir. Sistem dinamiği yaklaşımı ile hem işletmede gerçekleşen faaliyetlerin birbirine olan etkisi hem de muhasebede gerçekleşen olayların mali tablolara olan etkisi aynı anda izlenebilecektir. Böylelikle öğrenciler gerçekleşen işlemlerin bilanço, gelir tablosu, nakit akış tablosu ve diğer finansal tabloların birbiri ile olan ilişkisini kolaylıkla görebileceklerdir. Bu çalışmanın amacı başta finansal muhasebe dersi olmak üzere muhasebe alanı derslerinde sistem düşüncesi ve sistem dinamikleri yaklaşımlarının kullanımını ortaya çıkarmaktır. Bu amaca yönelik olarak çalışmada muhasebe derslerinde kullanılan örneklerin sistem dinamiği ile nasıl öğretileceğine dair uygulamalar VENSIM PLE 8.2 programı kullanılarak oluşturulmuştur ve muhasebe derslerinin izlencesinde muhtemel bir yöntem olarak tavsiye edilmektedir.

Anahtar Kelimeler: Muhasebe eğitimi, sistem düşüncesi, sistem dinamikleri.

JEL Sinıflandırması: I23, M10, M40.

The Usage of System Thinking And System Dynamics Approach in Accounting Courses: A Model Proposal For Financial Accounting Courses

ABSTRACT

The need to update the teaching methods and techniques used in accounting education in accordance with the requirements of the age is increasing. However, when the literature is examined, it is seen that the teaching methods recommended for use in accounting education are limited to computer use, PowerPoint use, case analysis and accounting package programs. Unlike these methods, system thinking and the system dynamics approach can be used as a new teaching method in teaching accounting courses. With the system dynamics approach, both the effects of the activities taking place in the business on each other and the effects of the events taking place in the accounting on the financial statements can be monitored simultaneously. Thus, students will be able to easily see the relation of real transactions to balance sheet, income statement, cash flow statement and other financial statements. The purpose of this study is to reveal the use of system thinking and system dynamics approaches in accounting field courses, in particular financial accounting course. For this purpose, the applications of how to teach the examples used in the accounting lessons with system dynamics are shown by using VENSIM PLE 8.2 programme and it is recommended as a possible method in the course of accounting lessons in the following periods.

Keywords: Accounting education, system thinking, system Dynamics.

\footnotetext{
* Makale Gönderim Tarihi: 29.03.2021, Makale Kabul Tarihi: 26.05.2021 , Makale Türü: Nicel Araştırma

** Prof. Dr., Sakarya Üniversitesi, İşletme Fakültesi, Emekli Öğretim Üyesi melekakgun@sakarya.edu.tr, ORCID: 0000-0002-5261-0682.

*** Dr. Öğr. Üyesi, Ardahan Üniversitesi, İktisadi ve İdari Bilimler Fakültesi, mervekiymaz@ardahan.edu.tr ORCID: 0000-0002-4953-9555.
} 


\section{GíRiş}

Günümüzde yaşanan teknolojik gelişmeler ve online eğitimin yoğun bir şekilde kullanılması, eğitim anlayışııın değişmesine neden olmuştur. $\mathrm{Bu}$ değişim bütün eğitim programlarını etkilediği gibi muhasebe eğitimini de etkilemektedir. Ortaya çıkan bu etkiye ve gelişmelere uyum sağlayabilmek için muhasebe eğitimi alanında; ders programlarının güncellenmesi, eğitim öğretim materyallerinin etkin bir şekilde kullanılması ve öğretim elemanlarının çağın gereklerini karşılayacak donanıma sahip olmaları gerekmektedir (Türegün ve Kaya, 2019: 340).

Lisans eğitimi sırasında genellikle iki yarıyılda verilen Finansal Muhasebe dersi pek çok öğrenci için sıkıcı, karmaşık ve zor kabul edilir (Martinis ve Tidd, 2011: 432; Friedlan, 1995; Akpınar ve Yıldız, 2018: 96). Oysa özellikle işletme eğitimi alan öğrenciler için iş yaşamlarında oldukça önemli bir yer tutacak olan muhasebe konusunda yeterli nosyonu kazanamadan mezun olmaları önemli bir sorundur. Finansal muhasebenin temel amacının finansal tabloların hazırlanması (bilanço, gelir tablosu, nakit akış tablosu) olduğu kabul edilirse bu tabloların nasıl oluştuğunun anlaşılması da büyük önem taşımaktadır.

İşletme bölümlerinde öğrencilere analitik yeterlilikler kazandırılmasında muhasebe alan derslerinin önemli bir yeri bulunmaktadır. Bir veya ikinci sınıflarında genel muhasebe dersi ile tanışan öğrencilerin birçoğu için muhasebenin temel prensiplerini anlamak zor ve zaman alıcıdır. Bunun önemli bir nedeni muhasebe dersinin işleniş biçimidir. İşletmelerde meydana gelebilecek finansal karakterdeki olayların örneğin; nakit hareketleri, stok hareketleri, yatırım hareketleri gibi gruplar altında toplanarak bunlara ilişkin işleyiş̧in aktarılması da genellikle iki yarıyılı kapsamaktadır. Ayrıca dönem sonlarında bilanço gelir tablosu, nakit akım tablosu ve öz kaynak değişim tablosu gibi finansal tabloların öğrenci tarafindan hazırlanabilir hale gelmesi bununda ötesinde analiz edilip yorumlanması oldukça uzun zaman almaktadır. Bununla beraber finansal muhasebe, maliyet muhasebesi, yönetim muhasebesi ve finansal tablolar analizi gibi işletme bölümü öğrencilerinin mezun olduklarında en çok yararlanacakları kritik önem taşıyan derslerin sistem yaklaşımı içinde, bütünsel olarak ve birbirleri ile etkileşimi de içerecek biçimde daha kısa sürede simülasyon tekniği ile aktarılması mümkündür. Bu amaçla sistem dinamiği yaklaşımından yararlanmak uygun olabilir. Sistem düşüncesi sistemin parçalarını ayrı ayrı anlamak yerine bu parçaların birbirleri ile olan ilişkilerini göz önünde bulundurarak problemlere çözüm arayan bir yaklaşımdır. Sistem düşüncesinin odaklandığı nokta bütünü oluşturan parçaların birbirleri ile olan bağlantıları ve ilişkilerdir ve tüm yaşayan karmaşık sistemlerin, öncelikle birbiriyle bağlantılı yapısını açıklar. Bu çalışmanın amacı başta finansal muhasebe dersi olmak üzere muhasebe alanı derslerinde sistem düşüncesi ve sistem dinamikleri yaklaşımlarının kullanımının tartışılması ve önümüzdeki dönemlerde muhasebe derslerinin anlatımında alternatif bir yöntem olarak kullanılmasını önermektir. Bu kapsamda endüstriyel simülasyon yazılımı olan VENSIM PLE programı ile muhasebe dersleri için örnekler oluşturulmuştur. Örneklerin bir modelleme aracı vasıtasıyla sunulmasının sonucunda öğrenciler tarafindan zor ve karmaşı olarak algılanan muhasebe derslerinin daha kolay anlaşılması ve muhasebe sisteminin bir bütün olarak görülmesini sağlamayı amaçlamaktadır. Böylelikle hem muhasebe 
derslerini anlamak öğrenciler açısından kolay bir hale gelmekte hem de ileriki çalışmalara yeni bir model önerisi olarak literatüre katkı sunulmaktadır.

\section{LITERATÜR TARAMASI}

Sistem dinamiği ile ilgili literatür incelendiğinde Forrester'ın bu konuda öncü olduğu söylenebilir. Forrester’ın “Endüstri Dinamiği” kavramını ilk defa kullanıldığı çalışmasında; bir firmanın üretiminde meydana gelen değişiklikler ile iş döngüsü arasındaki ilişki ortaya çıkarılmıştır (Forrester, 1961: 13-15). Şehir ekonomisi ve ev fiyatları arasındaki ilişkinin incelendiği "Şehir Dinamiği”; dünyadaki kaynakların y1llar içinde nüfus ve endüstrileşmeye bağlı olarak nasıl değiştiğini gösteren "Dünya Dinamiği” de Forrester'ın çalışmaları arasındadır (Forrester, 1969; Forrester, 1972).

Muhasebe sisteminin temel ilkelerinin sistem dinamiği ile açıklandığı çalışmada Yamaguchi finansal tabloları sistem dinamiğine uygun bir şekilde tasarlayarak, kullanıcıların sistemi bir bütün halinde görebilecekleri ve analiz edebilecekleri forma dönüştürmüştür. (Yamaguchi, 2003: 1). Schwarz ise çalışmasında çoğunlukla yönetim muhasebesi ve kontrol sistemlerine yönelmiştir. Bu kapsamda Schwarz yeni kurulan bir firmanın yönetim birimi için sistem dinamiği modeli oluşturmuş ve modelin simülasyon sonuçlarının firmanın finansal performansını tutarlı bir şekilde ortaya çıkardığını tespit etmiştir (Schwarz, 2002: 2). Shwarz ve Yamaguchi gibi Melse de finansal muhasebe ve yönetim muhasebesinin işletmenin gereksinimlerini karşılayacak şekilde sistem dinamiği ile modellenebileceğini çalışmasında aktarmıştır (Melse, 2006: 2). Sistem dinamiğinin işletme performansını ölçme, kar payı dağıtım politikalarının açıklanması, firma değerinin artırılması için gerekli yatırımların modellenmesi, sürdürülebilir büyüme yaklaşımlarının kurgulanması gibi işletmelerin ihtiyaç duyacağ1 pek çok alanda kullanımı mevcuttur (Moscardini, Loutfi ve Al-Quirem, 2005: 3; Qureshi, 2007: 24). Sistem dinamiği modeli muhasebe alanında sadece finansal muhasebe ve yönetim muhasebesi ile sınırlı kalmamış, stratejik maliyet yönetimi alanında da uygulaması bulunmaktadır. Aksu çalışmasında sistem dinamiğini sadece sabit ve değişken maliyet analizi değil aynı zamanda nedensel döngü ve stok akış diyagramları ile değişkenler arasındaki ilişkinin kolay ve etkili bir şekilde izlenebileceğini de belirtmiştir. Ayrıca sistem dinamiği modelinin stratejik maliyet yönetimi alanında kullanılmasıyla yöneticilerin faaliyetler başlamadan önce stratejik kararlarda ihtiyaç duyacağı bilgiyi elde edeceğini ve olası senaryoların sonuçlarının neler doğuracağını bir bütün halinde görmesine yardımcı olacağı da çalışma kapsamında belirtilmiştir (Aksu, 2013: 29). Üretim işletmelerinde sistem dinamiği modelinin kurgulandığı çalışmada Aksu ve arkadaşları farklı farklı üretim işletmesi modeli kurgulayarak sistem dinamiği modelinin üretim işletmelerine olan uygunluğunu ortaya çıkarmışlardır (Aksu, Söyler ve Eren, 2014: 97). Akgün ve Can ise pazarlama karması unsurları için bir bütçe döneminde verilen kararların dönem kârı veya zararı ve nakit akışı üzerindeki muhtemel etkilerini sistem dinamiği yaklaşımı ile modellemişlerdir (Akgün ve Can, 2016: 1). Ayrıca Eren Şenaras sistem dinamiği modelinin su kaynakları yönetimi için kullanımını önerdiği çalışmasında, sistem dinamiğinin karmaşık ve birbiri ile entegre konuların anlaşılabilirliği ve öğrenmeyi hızlandıran yönünü ortaya çıkarmıştır (Eren Şenaras, 2017: 1). 
Sistem dinamiği modeli sadece işletme ve muhasebe alanında değil işlem karmaşıklığının yaşandığı pek çok alanda kullanılabilir. Sistem dinamiği modelinin disiplinler arası çalışmalarda ön plana çıktığı görülmekle birlikte bu alanlardan bazıları Tablo 1'de gösterilmiştir.

Tablo 1. Sistem Dinamiği Yaklaşımının Kullanıldığı Alanlar

\begin{tabular}{|c|c|c|}
\hline Alan & Stoklar & Akışlar \\
\hline $\begin{array}{c}\text { Matematik, Fizik } \\
\text { ve Mühendislik }\end{array}$ & $\begin{array}{c}\text { İtegraller, Durumlar, Durum } \\
\text { değişkenleri ve stoklar }\end{array}$ & $\begin{array}{c}\text { Türevler, Değişim oranları, } \\
\text { Akışlar }\end{array}$ \\
\hline Kimya & Reaktifler ve Tepkime ürünleri & Reaksiyon hızları \\
\hline İmalat & İç stoklar, Envanterler & Üretim hızı \\
\hline Ekonomi & Seviyeler & Oranlar \\
\hline Muhasebe & Stoklar, Bilanço Kalemleri & Nakis Aşları \\
\hline
\end{tabular}

Kaynak: (Eren Şenaras, 2017: 679)

Muhasebe eğitimi alanında literatür incelendiğinde, muhasebe eğitimi ile ilgili çalışmaların iki ayrı yönde toplandığını görmek mümkündür. Özellikle son yıllarda Uluslararası Finansal Raporlama Standartlarının yürürlüğe girmesi ile birlikte standartlara uygun eğitim verilmesi gerektiği konusu literatürde kendini göstermektedir. Diğer bir yanda ise teknolojik gelişmeler ve bilişim çağının etkisi de göz önünde bulundurularak muhasebe eğitiminin nasıl olması gerektiği ve muhasebe eğitiminde öğrenme stilleri, muhasebe eğitimi ile ilgili öne çıkan başlıklar arasındadır.

Eren ve arkadaşları bilgi teknolojilerinde ortaya çıkan gelişmelerin muhasebe bilgi sitemini de etkilediğini vurguladığı çalışmasında, Türkiye'deki üniversitelerde ders müfredatları oluşturulurken teorik derslerin yanı sıra bilgi teknolojilerinin kullanıldığı derslere de yer verilmesi gerektiğini vurgulamıştır (Eren, Salur ve İyibildiren, 2020: 645).

Duman ve arkadaşlarının Türkiye'de yürürlüğe giren Türkiye Muhasebe Standartları (TMS)'ye göre muhasebe eğitiminde yapılması gereken değişiklikleri ele aldıkları çalışmalarında; Türk Vergi Kanunlarında gerekli düzenlemenin yapılması ve KGK'nın TMS/TFRS'ye uygun Tek Düzen Hesap Planı'nı hazırlayarak literatürde ve uygulamada birliği sağlaması gerektiği sonucuna varmışlardır (Duman, Bezirci, Yücenurşen, \& Apak, 2016: 371-372). Sürekli eğitim kapsamında muhasebe eğitiminin önemine değindiği çalışmasında (Şengel, 2010: 91) eğitimin sadece eğitim kurumları ile sınırlı olmadı̆̆1 ve yaşam boyu öğrenme zorunluluğunun insanların kendilerini geliştirme ihtiyacı içerisine girmesine neden olduğunu vurgulamıştır. Apak ve arkadaşları 2005-2015 yılları arasında Türkiye'de düzenlenen Muhasebe Eğitim Sempozyumu'nda sunulan bildirileri incelediği çalışmalarında, muhasebe eğitiminin teknolojik gelişmelere, uluslararası standartlara ve çağın 
gereklerine uygun olarak yapılandırılması gerektiği sonucuna varmışlardır (Apak, Duman, Özpeynirci, \& Karakışla, 2016: 186).

Muhasebe eğitimi alan öğrencilerin beklenilenlerine yer verdikleri çalışmalarında (Yücel, Saraç ve Çabuk, 2012: 103) geleneksel muhasebe eğitiminde çağın gereklerine uygun şekilde bazı değişikliklerin yapılması gerektiğine vurgu yapmışlardır. Ayrıca Uludağ Üniversitesi İktisadi ve İdari Bilimler Fakültesinde eğitim gören öğrenciler ile yapılan ve öğrenci beklentilerinin değerlendirildiği anket çalışmasında verilen muhasebe eğitiminin yeterli olmadığı ve daha kaliteli bir eğitim için neler yapılması gerektiği çalışma kapsamında değerlendirilmiştir. Muhasebe eğitimi alan öğrencilerin bakış açılarının değerlendirildiği bir diğer çalışmada Çelenk ve arkadaşları öğrencilerin muhasebeye, muhasebe eğitimine ve muhasebe eğitimi aldıktan sonra meslekle ilgili bakış açılarını değerlendirdiği çalışmanın sonuçlarında muhasebe mesleğine yönelen öğrencilerin çoğunun bu kararı üniversitede verdikleri tespit edilirken, büyük bir kısmı ise muhasebe alanında çalışan tanıdıklarının etkisi olduğu tespit edilmiştir (Çelenk, Atmaca ve Horasan, 2010: 170).

Polat ve arkadaşları öğrenme stillerinin doğuştan olduğu ve insanların öğrenme sürecini etkilediğini savunmaktadır. $\mathrm{Bu}$ kapsamda çalışmada öğrenme stilinin etkisini muhasebe eğitimi alan öğrenciler üzerinden açıklamak amaçlanmıştır. Bu amaç doğrultusunda Aksaray Üniversitesi İktisadi ve İdari Bilimler Fakültesi öğrencilerine anket uygulanarak öğrencilerin öğrenme stilleri ile performans arasındaki ilişki ortaya çıkarılmaya çalışılmıştır (Polat, Peker, Özpeynirci ve Duman, 2015: 1841). Muhasebe eğitimi ile ilgili uluslararas1 alanda yapılan çalışmalar kısaca şöyledir: Muhasebe eğitiminin kalıcı olması için sadece ders programlarının değil eğiticilerin, öğrencilerin beklentilerini göz önünde bulundurarak motive edilmesine vurgu yapılmıştır (Byrne ve Flood, 2005: 120). Muhasebe ders programlarının incelendiği çalışmada Cheng muhasebe eğitimi alanlar ile muhasebe eğiticilerinin beklentileri arasında büyük bir fark olduğu vurgulanmıştır. Ayrıca muhasebe eğitiminin çağın gereklerine uyum sağlaması gerektiği belirtilmiştir (Cheng, 2007: 581). Hurt muhasebe eğitiminde yeni eğitim anlayışına vurgu yapmış; Friedlan ise farklı öğretim yaklaşımlarının öğrencilerin muhasebe derslerindeki başarısına olan etkisini çalışmasında değinmiştir (Hurt, 2007: 295; Friedlan, 1995: 13).

\section{MUHASEBE EĞİTIMI}

Muhasebe eğitiminin gelişimine kısaca bakıldığında; ilk olarak 1868 yılında "Mektebi Mülkiyeyi Şahane" okulunda verilmeye başladığı görülmektedir. İlerleyen yıllarda muhasebe eğitiminin kapsamı gelişmeye başlamış ve 1883 yılında kurulan "Hamidiye Yüksek Ticaret Mektebi'nde muhasebe eğitimi verilmeye başlamıştır. Cumhuriyet döneminde ise üniversitelere muhasebe eğitimi veren kürsüler oluşturulmuş ve 1960 yılından itibaren muhasebe eğitimi gerek üniversitelerde gerek liselerde gerekse özel eğitim kurumlarında verilmeye devam etmektedir (Özdoğan, 1978: 12; Beyazıtlı, 2000: 40; Demirci, Kıymaz ve Ağsakal, 2015: 265).

Muhasebede üretilen bilgilerin karar alma süreçlerinde kullanılması için öğrencilerin muhasebe sürecini çok iyi kavramaları gerekmektedir. Muhasebe meslek eğitiminin kalitesi, öğrencilerin mesleğin gerektirdiği teknik becerilerle birlikte meslek ahlakını da kazanmalarını sağlayabilir. Bu bağlamda muhasebe eğitiminin kalitesi; öğretim elemanı, öğrenci, ders programlarının eş zamanlı olarak iş birliğine bağlıdır. Ders programları ve içerikler 
belirlenirken öğrenciler tarafından en iyi anlaşılacak yöntemler kullanılması kalıcı öğrenmenin sağlanması için önemli bir faktördür (Zaif ve Ayanoğlu, 2007: 118).

Muhasebe biliminin gelişmesi muhasebe eğitiminde de yeni bakış açıları ve yöntemlerin kullanılmasına olanak sağlamaktadır. Etkili bir muhasebe eğitimi; öğrenme ve öğretme sürecinde gerekli olan bilgilerin aktarılmasının yanı sıra öğrencilerin aldıkları bilgiyi kullanabilme becerisinin de geliştirilmesine bağlıdır. Bu bağlamda iyi bir muhasebe eğitimi sadece teorik bilginin verilmesi ile sağlanamaz. Teorik bilginin yanı sıra öğrencilerin problem çözme, zamanı etkili kullanma, takım çalışması ve iletişim gibi yeteneklerinin geliştirilmesi sağlanmalıdır (Kaytmazbalsarı ve Aslantürk, 2007: 245).

Muhasebe eğitiminde amaç, gerek duyulan bilgi ve becerinin uygulamalı olarak öğrenciye aktarılmasıdır. Bilginin ögrenciye başarılı bir şekilde aktarılması ise öğrencilerin konuyu kolaylıkla kavrayabilecekleri yöntemlerin tespit edilip kullanılmasılyla mümkün olacaktır (Gönen, 2016: 67). Muhasebe eğitiminde sistem dinamiğinin kullanılması tam da bu noktada ortaya çımakta ve bilginin öğrenciye aktarılması aşamasında kullanılması beklenen bir yöntemdir.

Ülkemizde muhasebe eğitiminde teorik ve pratik bilgi bir bütün olarak öğretilmektedir. Ancak sadece teorik ve pratik bilgi günümüz koşullarında yeterli değildir. Tam doğru ve güvenilir muhasebe bilgisine ulaşmak ise işbirlikçi öğrenme, tartışma ve vaka analizleri içeren kaliteli bir muhasebe eğitiminden geçmektedir (Polat, Peker, Özpeynirci ve Duman, 2015: 1841; Gönen, 2016: 68). Ayrıca muhasebe eğitimi verilirken teknolojik ve ekonomik gelişmeler, uluslararası standartlar, yasal düzenlemeler de dikkate alınmalıdır. Verilen eğitim sonrasında bireylere sadece bilgi üretme becerisi değil, üretilen bilgiyi analiz edip yorumlama kabiliyeti de verilmelidir (Alkan, 2015: 155). Muhasebe eğitimi esnasında dikkat edilmesi gereken bir diğer husus da etik kurallara ve toplumsal değerlere uygun şekilde davranılması gerektiğini içeren eğitimlerin de muhasebe eğitimi içerisinde yer alması gerektiğidir (Daştan ve Bellikli, 2016: 46).

Öğrenme malzemesi muhasebe eğitiminde öğrenmeyi etkileyen önemli unsurlardan bir tanesidir. Dolayısı ile öğrenme malzemesinin kolay, anlaşılabilir ve bütünü gösteren bir yapıya sahip olması gerekmektedir (Tazegül, Kutlu ve Elyıldırım, 2014: 35; Gönen, 2016: 69). Sistem dinamiği ise muhasebe eğitiminde olması gereken bu özelliklerin hepsini bir arada barındırması nedeniyle muhasebe eğitiminde kullanılması tavsiye edilen bir modeldir.

Muhasebe eğitimde öğrencilerin kazanması gereken yetkinlikler aşağıda sıralanmıştır (Kız1, 2003: 6; Gönen, 2016: 69):

$>\quad$ Bilgi sistemlerinin kurulması ve kullanılması,

> Karar alma becerisi,

> Finansal bilgi ve raporlama,

> İletişim yeteneği ve grup çalışması,

Mesleğe dair ahlaki sorumluluk, 
$>\quad$ Sosyal sorumluluk bilinci,

> Kültürel ve entelektüel birikim

Yapısı gereği eğitim sürekli değişen ve yenilenen faaliyetleri içermektedir. Eğitim faaliyetleri sonucunda ise hedeflenen çıktılara ulaşılmaya çalışılır. Muhasebe eğitiminde de işletmelerin ihtiyaç duyduğu nitelikte eleman yetiştirilmesi ise mesleki eğitime bağlıdır. Mesleki eğitimi alan birey ise sadece bilgi aktarımı becerisine değil, analiz ve yorum kabiliyetine de sahip olmalıdır. Dolayısı ile muhasebe eğitiminin bireysel farklılıkları gözeten, değişen şartlara uyum sağlayabilen ve "öğrenmeyi öğreten" bir yapıya sahip olması gerekmektedir (Tazegül, Kutlu ve Elyıldırım, 2014: 34).

\section{SİSTEM DÜŞÜNCESİ VE SİSTEM DİNAMİĞİ}

Sistem, sınırları belli olan ve birbiri ile ilişkili elemanların kümesi olarak tanımlanmaktadır (Sezen, 2009: 13). Sistem düşüncesi ise sisteminin bütününün açık bir şekilde görünmesine olanak sağlar ve sistem üzerinde yapılacak değişikliklerin izlenmesine yardımcı olur (Eren Şenaras, 2017: 674).

Sistem düşüncesi; "Organizasyonel karar ve davranışları içeren sistemleri oluşturan güçlerin, birbiri arasındaki ilişkileri incelemeye yönelik ve onları ortak bir işlevin parçası olarak algılayan metotlar, araçlar ve prensipler topluluğu" olarak ifade edilebilir (Eren Şenaras, 2017: 671). Sistem düşüncesinin temelinde; bütün sistemlerin davranış olarak ortak prensipleri izlediği yatmaktadır.

Sistem düşüncesi ve sistem dinamiği; iş, politika, ekonomi ve çevresel sistemlerin oluşturduğu karmaşa ve değişikliklerin altında yatan dinamiklerin açıklanmasında etkin olan kavramsal ve sayısal modelleme tekniğidir (Abdalbari, Elsawah ve Sahafi, 2015: 1; Maani ve Cavana, 2007: 18; Eren Şenaras, 2017: 672).

Sistem Dinamiği alanındaki çalışmalar son yıllarda oldukça artmıştır. Ülkelerin uzun dönemli ekonomi planlarından, firmaların satış stratejisi belirleme alanına kadar sistem dinamiği yaklaşımı kullanılmaktadır. Sistem Dinamiğinin bu denli yaygınlaşmasının en önemli sebeplerinden biri içinde bulunduğumuz yüzyılda "Sistem Yaklaşımı" kavramının hemen bütün alanlarda benimsenerek, sistem analizine olan ihtiyacin artmasıdır.

Sistem dinamiğinde model oluşturmak için, matematiksel denklemler ve bilgisayar yazılımları kullanılır. Model üzerindeki değişkenlerin yapısı bilgisayarda benzetim yapılarak elde edilir (Eren Şenaras, 2017: 673).

Sistem dinamiği, "sistemlerin anlatılması ve anlaşılmasını sağlama amaçlı, kalitatif ve kantitatif modelleri kullanan, davranışı oluşturan enformasyon geri bildirim tipini belirleyen, simülasyon ve optimizasyonla sağlam enformasyon geri bildirim yapısı ve kontrol politikasını belirleyen teknik" olarak tanımlanmaktadır (Aksu, Söyler, \& Eren, 2014: 74). Bu yaklaşım sayesinde işletmelerde alınan kararların değişkenler üzerindeki etkisini hem görsel olarak hem de simülasyon aracı vasıtasıyla bir bütün olarak görmek mümkündür (Akgün ve Can, 2016: 27). 
Sistem dinamiği sistem teorisinin bir alanıdır. Bu bağlamda sistem dinamiği karmaşık sistemlerin dinamik davranışlarının incelendiği bir yöntemdir. Bu yöntemin temel prensibi ise sistemin davranışlarının yine sitemin kendi yapısından kaynaklandığı ve bileşenler arasındaki ilişkinin bileşenler kadar önemli olduğudur. Çünkü sistemin davranışı sadece bileşenlerin tek başına ele alınması ile açıklanamadığı gibi, tekil bileşenlerin davranışlarından farklı olabilmektedir (Ögüt ve Şahin, 2012: 5; Eren Şenaras, 2017: 671).

Sistem dinamiğinde sistemin alt yapısını oluşturan birtakım araçlar vardır. Bunlardan en önemlileri nedensel döngü diyagramı ve stok akış diyagramıdır. Nedensel döngü diyagramı nedenler ile ilgili hipotezlerin ve bunlara ilişkin geri bildirimlerin izlenmesinde kullanılmaktadır. Ancak nedensel döngü diyagramı tek başına sistemi açıklamada yeterli olmamakta; sistemde bulunan birikimlerin ve akışların gösterilmesinde yetersiz kalmaktadır. $\mathrm{Bu}$ yüzden istenilen yapıyı ortaya çıkarmak için seviye değişim diyagramları kullanılmaktadır (Aksu, Söyler ve Eren, 2014: 75).

Sistem dinamiği modelinin belli aşamaları vardır. Bunlar (Yunna, Kaifeng, Yisheng ve FengTiantian, 2015: 236):

Sistemin yapısını unsurlarını ve bu unsurlar arasındaki ilişkinin anlaşılabilmesi için analiz yapmak. Bu analiz sayesinde sistemin sınırları, özellikleri ve yapısı açıkça ortaya konulmuş olur.

Sistemin mantıksal yapısının anlaşılabilmesi için akış diyagramları oluşturmak. $\mathrm{Bu}$ diyagramlar oluşturulurken seviye değişkenleri, oran değişkenleri ve yardımcı değişkenler gibi değişkenler kullanılır. Bu değişkenler ile analiz edilen nesnelerin doğası standart sembollerle belirtilmiş olur.

> Akış diyagramındaki değişkenler için denklem oluşturmak ve bunlar arasındaki niceliksel ilişkileri öğrenmek.

Akış diyagramları ve denklemleri bilgisayar simülasyon ortamına girerek modeldeki değişkenlerin sistem üzerindeki etkisini incelemek.

\section{SİSTEM DİNAMİĞíNIN YAPISI}

Sistem dinamiğinin yapısı dört faktörden oluşur (Forrester, 1969: 11-12). Bunlar:

> Sistem çevresindeki kapalı sınırın oluşturulması,

$>\quad$ Kapalı sınırlar içerisindeki temel yapısal elemanlar ve bunlara ilişkin geri bildirim döngüleri,

Geri bildirim döngüleri içerisinde yer alan stok seviye (durum) değişkenleri,

$>\quad$ Geri bildirim döngülerindeki oluşumları gösteren akış (oran) değişkenleri.

Sistem döngüsünde "bütün” kavramını geliştirmek için sistemin davranışlarını oluşturan etkileşimlerin bulunduğu sinırlar oluşturulmalıdır (Forrester, 1969: 12; Eren Şenaras, 2017: 677). Şekil 1'de dinamik bir sistemi tanımlayan kapalı sınır örneği gösterilmektedir. 


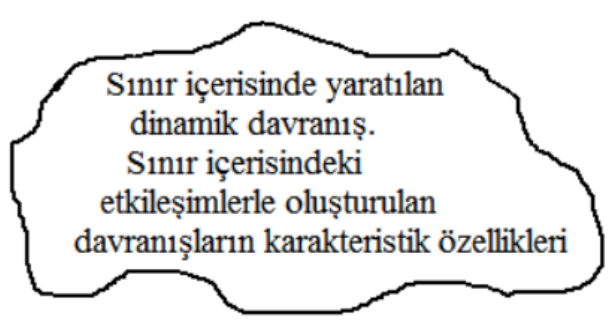

Şekil 1. Dinamik bir sistemi tanımlayan kapalı sınır

Kaynak: (Forrester, 1969: 12; Eren Şenaras, 2017: 677; Eren Şenaras ve Sezen, 2017: 43)

Sistem davranışını tanımlamak ve anlamlandırmak için Sistem Dinamiği dilini bilmek gerekmektedir. Sistem dinamiği dili Forrester tarafından yaratılmış olup Şekil'2 de gösterilmiştir. Sistem dinamiği dili; stoklar, akışlar, karar fonksiyonu ve bilgi akışları olmak üzere dört faktörden oluşmaktadır. Sistemi ne kadar karmaşı olursa olsun yukarıda belirtilen dört faktör sayesinde söz konusu sistemi anlamlandırmak mümkün olacaktır (Forrester, 1969; Eren Şenaras, 2017: 677; Eren Şenaras \& Sezen, 2017: 43).

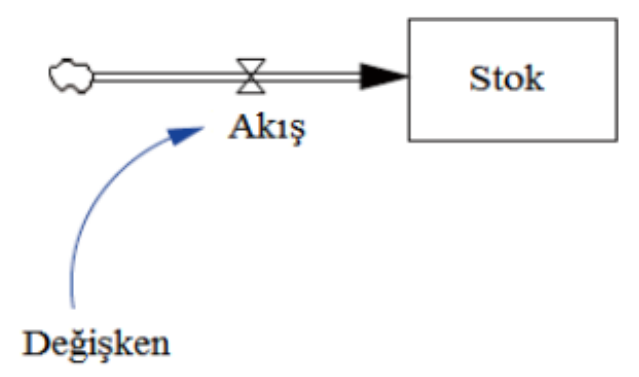

Şekil 2. Sistem Dinamiği Dili

Kaynak: Yamaguchi, 2020: 4; Eren Şenaras, 2017: 677

Sistem dinamiğini oluşturan dört faktörden en önemlisi stoklardır. Stoklar olmadan sistem tanımlanamaz. Çünkü sistem dinamiğinde model oluşturmak stokların birleşimi ile mümkün olmaktadır. Buradaki stok kavramını muhasebedeki stok kavramı ile karıştırmamak gerekir. Stok kavramı sistem dinamiğinde birikimleri temsil etmektedir. Örnek vermek gerekirse bir işletmenin istihdam ettiği personeller sistem dinamiği açısından bir stoktur. Aynı şekilde bir şehirde yaşayan insanlar da stoktur. Stoklar doğrudan değiştirilemezler, sadece akışlarla değişirler. Kısaca belirtmek gerekirse sistem dinamiğinde "stok" belli bir zamanda var olan nesnelerin toplamı olarak tanımlanır (Yamaguchi, 2020: 23). Stok yapısı Şekil 3’te gösterilmiş̧ir.

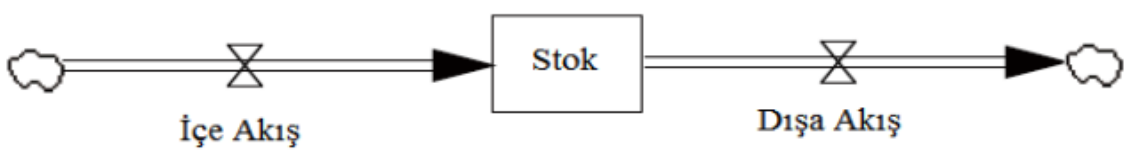

Şekil 3. Sistem Dinamiğinde Stok Yapıs1

Kaynak: Yamaguchi, 2020: 23; Eren Şenaras, 2017: 678

Akış ise birim zamanda stoktaki artış veya azalış olarak tanımlanır. Akış, zamanın iki nokta arasındaki miktar ile tanımlanırken; stoklar zamanın belli bir noktasındaki miktar olarak 
tanımlanmaktadır. Kısaca akış, stoğun değişim oranıdır ve stoktaki değişmeleri gösterir (Eren Şenaras, 2017: 678). Şekil 4'te stok ve akış arasındaki ilişki gösterilmiştir.

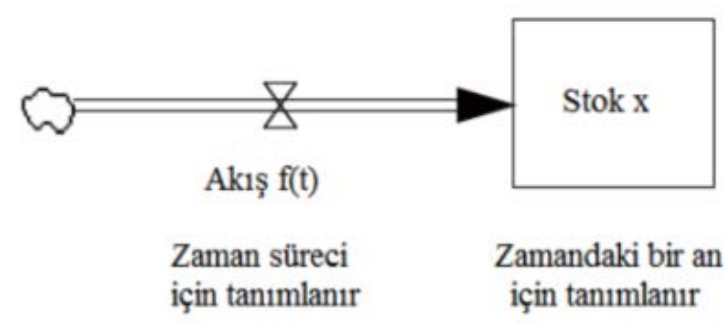

Şekil 4. Stok, Akış İlişkisi

Kaynak: Yamaguchi, 2020: 7; Eren Şenaras, 2017: 679

Sistem dinamiği dilinin diğer iki faktörü karar fonksiyonları ve bilgi akışlarıdır. Karar fonksiyonları ile stoklardaki bilgilerin karara dönüşümünü belirleyen politikalar belirlenir. Dinamik içerisinde verilen tüm kararlar bir eylem üretir ve akış oranı olarak da ifade edilir. Karar fonksiyonları ise stoklardaki bilgiye göre şekillenir.

\section{FİNANSAL MUHASEBE DERSLERİ İÇİN SİSTEM DİNAMİĞí MODELİ}

Muhasebe eğitimine yönelik öğrenci algılarının araştırıldığg çalışmalar göstermektedir ki muhasebe dersleri öğrenciler için anlaşılması zor ve sıkıcıdır (Akpınar ve Yıldız, 2018: 91; Friedlan, 1995: 47; Martinis ve Tidd, 2011: 432; Demirel Utku ve Erol, 2015: 91). Bu algının oluşmasında öğrencilerin muhasebe sistemini ve muhasebe sürecini bir bütün olarak algılayamamaları olabilir. Sistem dinamiği öğrencilere muhasebe sürecini bir bütün olarak göstermeye yardımcı olma noktasında etkin bir yöntemdir. Muhasebe derslerinde özellikle varlık ve kaynak hesaplarının birbirini nasıl etkilediği, maliyet yansıtma hesaplarının işleyişi ve devamında gelir-gider hesaplarının oluşumuna yönelik işleyiş sistem dinamiği modeli ile bir bütün olarak oluşturulabilir.

Çalışma kapsamında ortaya çıkarılan modellerin oluşturulmasında VENSİM PLE 8.2 programı kullanılmıştır. Şekil 5'te bilanço hesaplarının işleyiş mantığını açıklayan bir stokseviye diyagramı yer almaktadır. 


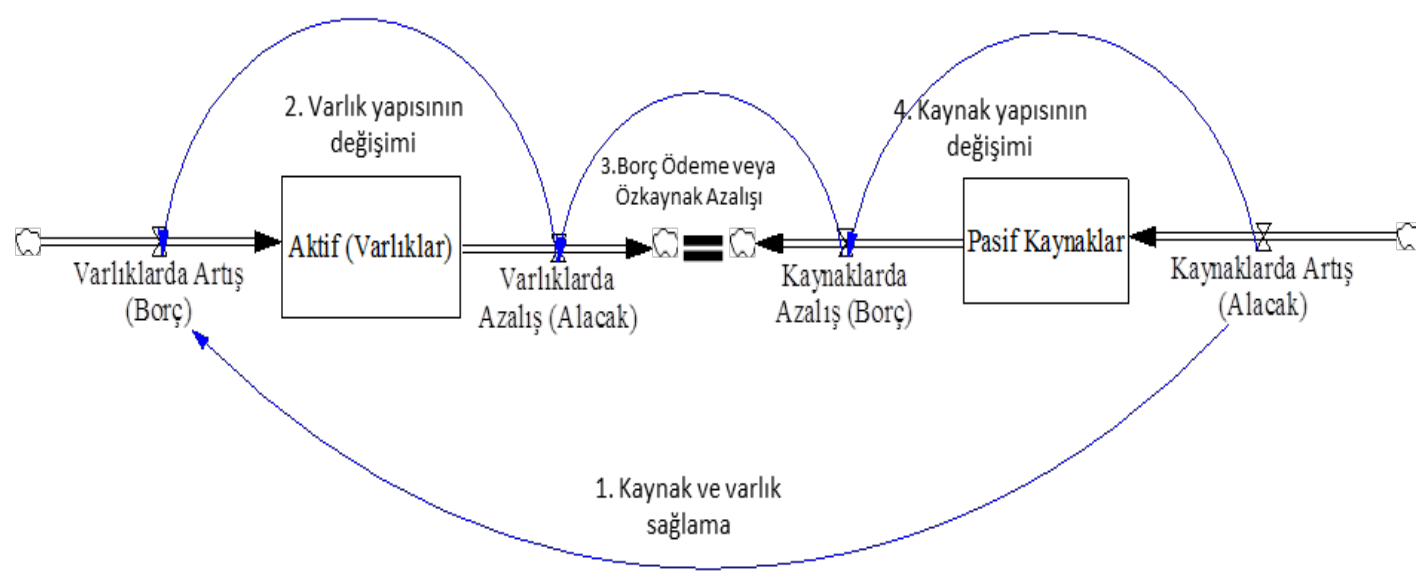

Şekil 5. Bilanço hesaplarının stok-seviye diyagramı

Şekil 5'te gösterilen modelde dikdörtgenler (stok) aktif ve pasif hesapların toplu olarak seviyesini göstermektedir. Çift çizgili oklar (akış) ise bu seviyelerdeki artış ve azalışları temsil eder. Dikdörtgenin içine doğru yönelmiş oklar seviyeyi artırırken dışına yönelen oklar seviyeyi azaltmaktadır. Aktif hesapları artıran işlemler bu hesapları borçlandırırken pasif hesapları artıran işlemler ise alacaklandırmaktadır. Sistem dinamiği taksonomisinde bu artış veya azalışları oranlar (rate) temsil etmektedir. Bu oranlar muhasebe sistemi için finansal karakterdeki olayları ifade etmektedir. Çift taraflı muhasebe sisteminde finansal karakterdeki bir olayın kaydedilmesi sırasında işlemin niteliğine uygun olarak en az iki hesabın kullanılması ve bu hesaplardan birinin borçlandırılırken diğerinin de alacaklandırılması gerekir.

Şekil 5 incelendiğinde bilanço hesaplarını ilgilendirilen işlemler diyagramda dört farklı başlık altında toplanmıştır. 1 nolu işlemde işletmeye tahsis edilen veya sağlanan kaynağın bir varlık olarak karşılığı bulunduğu ve kaynak hesabının işlemin özelliğine göre alacaklanırken varlık hesabının da aynı tutarda borçlanması gerektiği görselleștirilmiştir. 2 nolu işlem varlıkların kendi içinde nitelik değişitirmesini, 3 nolu işlem varlıklarda ve aynı anda kaynaklarda meydana gelebilecek azalışı, 4 nolu işlem ise kaynakların kendi içinde nitelik değiştirmesini ifade etmektedir. Bu işlemlerin tamamı bilanço hesaplarını ilgilendirir ve bu işlemlerin hiçbiri işletmede varlık ve kaynakların toplamında bir değişime neden olmaz. Diğer taraftan muhasebeyi ilgilendiren işlemlerin bir bölümü işletmelerde kar veya zarara neden olabilecek nitelik taşır ve bu işlemler gelir hesapları ile gider ve/veya maliyet hesaplarının da kullanılmasını gerektirir. Bunlar maliyet hesapları ve gelir tablosu hesaplarıdır. 


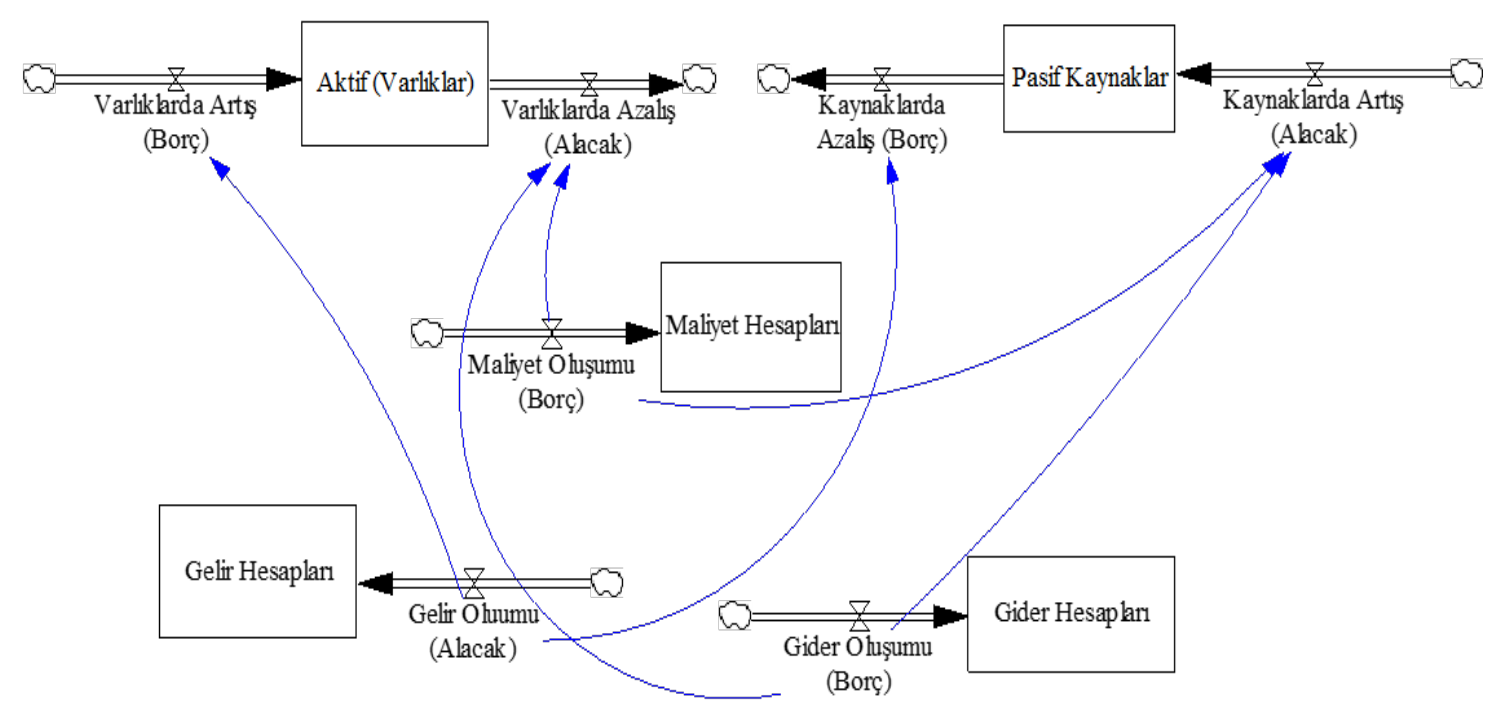

Şekil 6. Gelir, gider ve maliyet hesaplarının stok-seviye diyagramı

Şekil 6 gelir tablosu ve maliyet hesaplarının işleyişi sistem dinamiği stok-seviye diyagramında gösterilmiştir. $\mathrm{Bu}$ işleyiş dönem içinde gelir, maliyet ve giderlerin oluşumu sırasında yapılması gereken muhtemel kayıtların mantığını açıklamaktadır. Dolayısıyla varlık ve kaynaklardaki değişimin hem maliyet hesaplarını hem de gelir gider hesaplarını nasıl etkilediği şematik olarak izlenebilmektedir. Örneğin Şekil 6 incelendiğinde gelir oluşumunu etkileyen faktörlerin varlıklarda artış ya da kaynaklarda azalıştan meydana geldiği açıkça görülmektedir. Yine varlıklardaki azalışın nedeninin maliyet ya da gider oluşumundan kaynaklandığı görülmektedir. Kısaca belirtmek gerekirse Şekil 6 varlık hesapları, kaynak hesapları, maliyet ve gider hesaplarındaki artış ve azalışların kaynağını göstermektedir. 


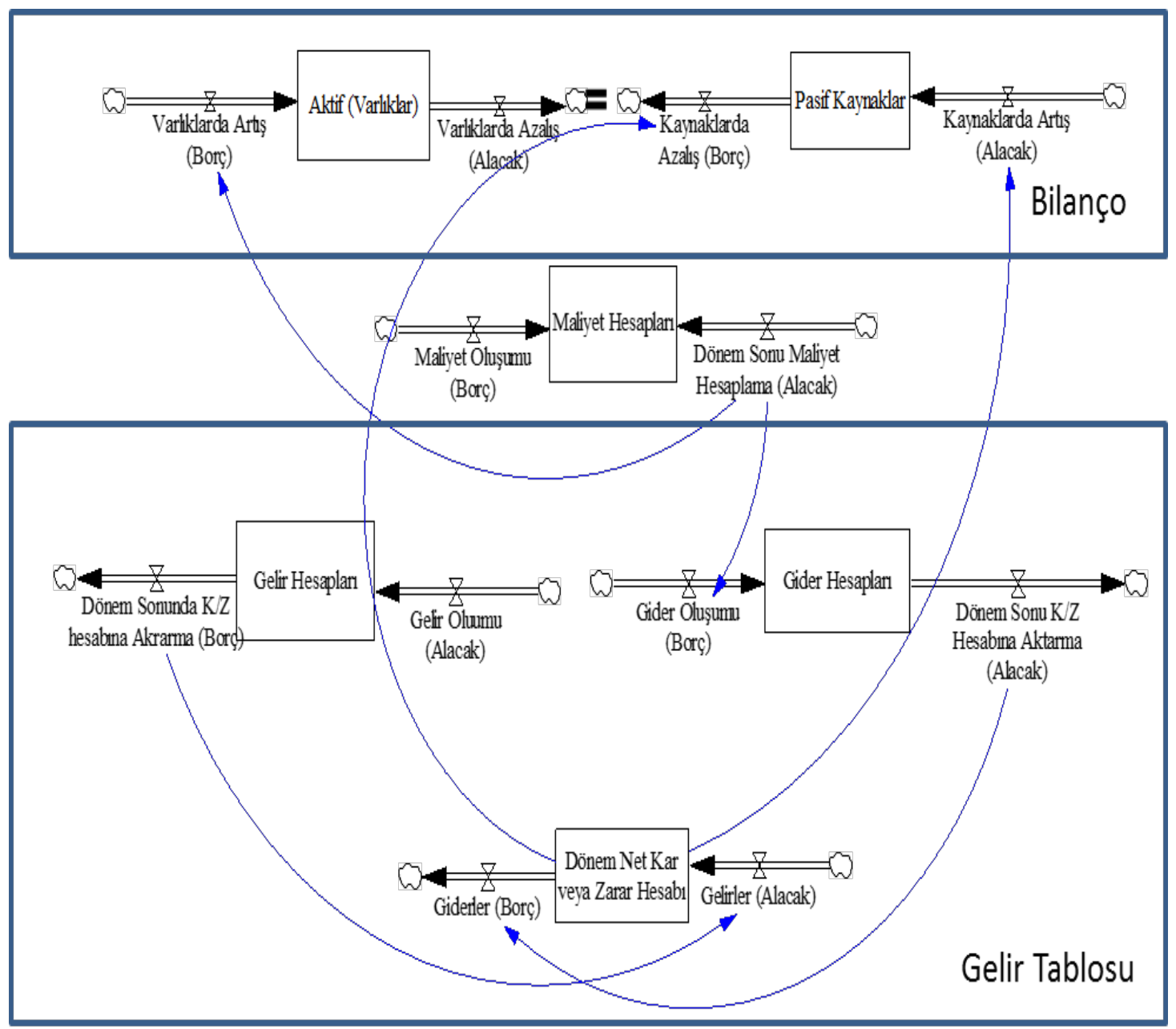

Şekil 7. Dönem sonu kapanış kayıtları stok-seviye diyagramı

Şekil 7'de ise muhasebe sistemi içerisinde gerekli olan bilanço hesaplarının gelir tablosu hesaplarını etkileme mantığı sistem dinamiği modellemesi ile gösterilmeye çalışılmıştır. Şekil incelendiğinde gelir oluşumunun alacak kaydıyla mümkün olduğu, dönem sonunda ise gelir hesaplarının borçlandırılarak Dönem Karı veya Zararı Hesabına aktarıldığı, devamında ise ortaya çıkan Dönem Net Kar veya Zararının kaynaklarda artış ya da azalışa neden olduğu görülmektedir. Aynı şekilde gider oluşumunun borç kaydiyla gerçekleştiği, dönem sonlarında alacak kaydı yapılarak gider hesaplarının Dönem Karı/Zararı hesabına aktarıldığı devamında ise ortaya çıkan Dönem Net Kar veya Zararının kaynaklarda artış veya azalışa neden olduğu görülmektedir.

Yukarıda gösterilen diyagramlar işlemin türüne göre farklılaştırılabilir ve çoğaltılabilir. Söz konusu diyagramların muhasebe derslerinin anlatımında kullanılmasıyla uzun bir dönem süren muhasebe süreci kolaylıkla izlenebilir. Daha en başta muhasebe sisteminin mantığını öğrenen öğrenciler ise diğer muhasebe alan derslerini daha kolay anlaması sağlanabilir.

\section{SONUÇ VE ÖNERILER}


Muhasebe eğitimi ile ilgili yapılan çalışmalar teknolojik gelişmelerle birlikte muhasebe eğitiminde kullanılan öğretim yöntem ve tekniklerin de çağın gereklerine uyum sağlaması gerektiğini göstermektedir. Özellikle online eğitimin ön plana çıktığı günümüzde sadece muhasebe eğitimi değil tüm eğitim öğretim programlarında bilgisayar teknolojilerinin ve simülasyon yöntemlerinin kullanılması oldukça artmıştır. Bu bağlamda sistem dinamiği yöntemi öğrencilerin muhasebe sürecini bir bütün olarak görmelerine olanak sağlayan bir model olarak kullanılması tavsiye edilmektedir.

Muhasebe derslerinde konular çoğu zaman parça parça anlatılmakta ve öğrenciler gerçekleşen işlemlerin bilanço, gelir tablosu, nakit akış tablosu ve diğer finansal tabloların birbiri ile ilişkisini bir bütün olarak görememektedir. Sistem dinamiği yaklaşımında ise daha en başta gerçekleşen işlemin mali tabloların hangisinde ve ne yönde bir etki yaratacağını görebilmek mümkündür. Çünkü sistem düşüncesi sistemin parçalarını ayrı ayrı anlamak yerine bu parçaların birbirleri ile olan iliş̧kilerini göz önünde bulundurarak problemlere çözüm arayan bir yaklaşımdır. Bu düşünce yaklaşımı ile öğrencilere bütüncül bir bakış açısı sunulmakta, bu sayede daha hızlı ve kolay öğrenmeleri sağlanmaktadır. Kısaca belirtmek gerekirse sistem dinamiği yaklaşımının muhasebe derslerinde kullanılması ile birlikte; bilanço hesaplarının işleyiş mantığı, gelir tablosu ve maliyet hesaplarının işleyişi, dönem sonu hesaplarının kapatılması ve döneme ilişkin net kar zararın oluşumunun bir bütün olarak ortaya çıkarılması mümkün olabilmektedir. Bu bağlamda sistem dinamiği yaklaşımı muhasebe derslerinde kullanılması tavsiye edilen alternatif bir yaklaşımdır. Bu çalışma kapsamında sistem dinamiği modeli oluşturulurken sadece temel kavramlar kullanılmış oranlar ve formüller dahil edilmemiştir. Çalışmada sunulan modeller üzerinde değişiklik yapılabilir daha fazla girdinin olduğu karmaşık modeller oluşturulabilir. İlerleyen çalışmalarda ise sistem dinamiği modelinin işletme faaliyetlerinde kullanımı; yönetim muhasebesi, maliyet muhasebesi derslerinin anlatımı için tasarlanması ve bu konudaki çalışmaların literatüre eklenmesi tavsiye edilmektedir.

\section{KAYNAKLAR}

Abdalbari, Hassan - Elsawah, Sondoss - Sahafi, Kamran (2015), "Model Learning Using Genetic Programming Under Full And Partial System Information Conditions”, 33rd International Conference of the System Dynamics Society, Cambridge, Massachusetts, USA.

Akgün, Melek - Can, Ahmet Vecdi (2016), "Pazarlama Karması Stratejilerinin Etkileşimli Yapısı ve Finansal Performans Üzerindeki Etkileri”, Süleyman Demirel Üniversitesi Sosyal Bilimler Enstitüsü Dergisi CiEP Özel Sayısı, ss.12-29.

Akpınar, Sema - Yıldız, Şule (2018), "Muhasebe Eğitimi Alan Öğrencilerin Muhasebe Algılarına Yönelik Metaforlar, Muhasebe ve Finansman Dergisi, ss.91-114.

Aksu, İbrahim (2013), “ Syestem Dynamics Approach As a Tool of Strategic Cost Management”, The International Journal of Social Sciences, 15(1), ss.18-30.

Aksu, İbrahim - Söyler, Hasan - Eren, Miraç (2014), "Üretim İşletmesi Sistem Dinamiği Modeli”, Selçuk Üniversitesi İktisadi ve İdari Bilimler Fakültesi Sosyal ve Ekonomik Araştırmalar Dergisi, 14(28), ss.69-104. 
Alkan, Gönül (2015), “İşletmelerin Ön Lisans Muhasebe Eğitiminden Beklentileri: İzmir’de Bir Araştırma", Muhasebe Bilim Dünyası Dergisi, 17(1), ss.137-158.

Apak, İbrahim - Duman, Haluk - Özpeynirci, Rabia - Karakışla, Enver (2016), “Türkiyede Muhasebe Eğitimi: Türkiye Muhasebe Eğitimi Sempozyumu Örneği”, International Journal of Human Sciences, 13(1), ss.169-197.

Beyazıtlı, Ercan (2000), “Türkiye'de Muhasebe Eğitimi”, Uluslararası Muhasebe Eğitimi Konferans1, Gelecek Yüzyılda Muhasebe Eğitimi, Ankara: TÜRMOB Yayınları, Yayın No 139, ss.39-59.

Byrne, Marann - Flood, Barbara (2005), "Study of Accounting Students' Motives, Expectations And Preparedness For Higher Education”, Journal of Further and Higher Education, 29(2), pp.111-124.

Cheng, Kai-Wen (2007), “The Curriculum Design In Universities From The Perspective Of Providers In Accounting Education”, Education, 127(4), pp.581-590.

Coyle, Geoff (1996), System Dynamics Modelling: A Practical Approach, Chapman \&Hall, First Edition.

Çelenk, Hakan - Atmaca, Metin - Horasan, Emre (2010), “Marmara Üniversitesi'nde Muhasebe Eğitimi Alan Öğrencilerin Muhasebe Alanına Bakış Açılarının Değerlendirilmesine Yönelik Bir Araştırma”, Öneri Dergisi, 9(33), ss.159-171.

Daştan, Abdulkerim - Bellikli, Uğur (2016), "Muhasebe ve Finansal Raporlama Standartları Eğitiminde İdeal Arayış: Türkiye'de Bir Araştırma", 35. Türkiye Muhasebe Eğitim Sempozyumu, Gazimagusa, Kibrıs, 27 Nisan - 01 Mayıs 2016, ss.45-84.

Demirci, Şuayyip Doğuş - Kıymaz, Merve - Ağsakal, Ahmet (2015), "Yüksek Öğretimde Verilen Muhasebe Eğitiminin Muhasebe Mesleğine Giriş Sınavlarına Katkısı : Devlet Üniversiteleri İşletme ve Muhasebe Bölümleri Üzerine Bir Araştırma", Gümüşhane Üniversitesi Sosyal Bilimler Elektronik Dergisi, 6(13), ss.264-280.

Demirel Utku, Burcu - Erol, İbrahim (2015), "Lisans Öğrencilerinin Muhasebeye Giriş Dersine Yönelik Algılamalarının Belirlenmesi”, Journal of Accounting, Finance and Auditing Studies, 1(3), ss.91-104.

Duman, Haluk - Bezirci, Muhammet - Yücenurşen, Mehmet - Apak, İbrahim (2016), “Türkiye Muhasebe/Finansal Raporlama Standartlarına Göre Günümüz Muhasebe Eğitiminden Beklentiler”, International Journal of Human Sciences,13(1), ss.364-374.

Eren, Tevfik - Salur, Mehmet Nuri - İyibildiren, Mustafa (2020), "Muhasebe Eğitiminde Bilgi Teknolojisi Kullanımı: Türkiye'deki Üniveristeler Üzerine Bir Araştırma”, Muhasebe Bilim Dünyas1 Dergisi, 22(4), ss.668-668.

Eren Şenaras, Arzu (2017), "Su Kaynakları Yönetimi İçin Bir Öneri: Sistem Dinamiğgi”, İşletme Araştırmaları Dergisi, 9(3), ss.668-692. 
Eren Şenaras, Arzu - Sezen, H. Kemal (2017), "Sistem Düşüncesi”, Journal of Life Economics, 4(1), ss.39-58.

Forrester, Jay Wright (1961), Industrial Dynamics, Cambridge: MIT Press. http://www.laprospective.fr/dyn/francais/memoire/autres_textes_de_la_prospective/au tres_ouvrages_numerises/industrial-dynamics-forrester-1961.pdf Erişim Tarihi: 24.05.2021

Forrester, Jay Wright (1969), Urban Dynamics, Cambridge MA: Productivity Press.

Forrester, Jay Wright (1972),World Dynamics, Massachussets: Wright-Allen Press.

Friedlan, John (1995), “The Effects Of Different Teaching Approaches On Students' Perceptions Of The Skills Needed For Success In Accounting Courses And By Practicing Accountants”, Issues in Accounting Educational Technology, 10(1), pp.4763.

Gönen, Seçkin (2016), "Önlisans Düzeyinde Eğitim Gören Öğrencilerin Muhasebe Eğitiminden Beklentilere Yönelik İzmir Ve Denizli İllerinde Bir Araştırma", Uluslararası Alanya İşletme Fakültesi Dergisi, 8(2), ss.67-78.

Hurt, Bob (2007), "Teaching What Matters: A New Conception of Accounting Education”, Journal of Education for Business, 82(5), pp.295-299.

Kaytmaz Balsarı, Çağnur - Aslantürk, Banu Esra (2007), "KavramHaritaları ve Muhasebe Eğitimi, Yönetim Muhasebesi Uygulaması”, XXVI.Türkiye Muhasebe Eğitimi Sempozyumu, Antalya.

Kızıl, Ahmet (2003). "Muhasebe Eğitiminde Son. Gelişmeler", XXII. Türkiye Muhasebe Eğitimi Sempozyumu, Antalya, ss.3-20.

Maani, Kambız - Cavana, Robert (2007), Systems Thinking And Modelling Understanding Change and Complexity, Pearson Education: NewZealand.

Martinis, Karen - Tidd, Ronald (2011), "Does Performing Additional Work Improve A Student’s Accounting Principles Grade? First Analysis”, ASBBS Annual Conferance.

Melse, Eric (2006), “The Financial Accounting Model from a System Dynamics Perspective. MPRA Paper”, 7624, University Library of Munich, Germany. https://mpra.ub.unimuenchen.de/7624/1/MPRA_paper_7624.pdf adresinden alındı, Erişim Tarihi: 26.05.2021

Moscardini, Alfredo - Loutfi, Mohamed - Al-Quirem, Raed (2005), "The Use of System Dynamics Models to Evaluate the Credit Worthiness Of Firms”, 23rd International Conference of The System Dynamics Society, Boston.

Ögüt, Kaan - Şahin, Sercin (2012), “Türkiye'de Finansal İstikrar Sorununa Sistem Dinamiği Yaklaşımı", Türkiye Ekonomi Kurumu Uluslararası Ekonomi Konferansı, İzmir. 
Turanlı Özdoğan, Seher (1978), Muhasebe Öğretimi Metotları El Kitabı, Ankara: Ticaret ve Turizm Yüksek Öğretmen Okulu Yayınları.

Polat, Yusuf - Peker, Ali Aykut - Özpeynirci, Rabia - Duman, Haluk (2015), “The Effect Of Learning Styles Od Accountng Eduction Students On Their Performance: A Field Study”, Procedia - Social and Behavioral Sciences (174), pp.1841-1848.

Qureshi, Muhammad Azeem (2007), "System Dynamics Modelling Of Firm Value”. Journal of Modelling in Management, 2(1), pp.24-39.

Schwarz, Rainer (2002), “An Elementary Dynamic Model Of A Small Start-Up Firm”, 20th International Conference of the System Dynamics Society, Palermo, Italy.

Sezen, Hayrettin Kemal (2009), Yöneylem Araştrmasında Benzetim. Bursa: Ekin Yayınevi.

Sterman, John D. (2000), Business Dynamics Systems Thinking And Modelling In A Complex World, Mcgraw-Hill, New York.

Şengel, Salim (2010), "Sürekli Muhasebe Meslek Eğitiminin Önemi ve Bir Değerlendirme", Muhasebe ve Finansman Dergisi, ss.81-94.

Tazegül, Alper - Kutlu, Hüseyin Ali - Elyıldırım, Ümit Yaşar (2014), "Yeni Yaklaşımlar ve Öğrenme-Öğretme Etkinlikleri- Muhasebe Öğretiminde Öğrenci Merkezli Yöntemler ve Araçlar", 33.Türkiye Muhasebe Eğitimi Sempozyumu Bildiri Kitabı, Antalya: Anadolu Üniversitesi İşletme Fakültesi Yayınları, ss.31-53.

Türegün, Nida - Kaya, Can Tansel (2019), "Küreselleşmenin Türkiyedeki Yükseköğretim ve Muhasebe Eğitimi Üzerindeki Etkileri”, Yükseköğretim ve Bilim Dergisi, ss.335-341.

Yamaguchi, Kaoru (2003), "Principle of Accounting System Dynamics-Modeling Corporate Financial Statements”, 21st International Conference of the System Dynamics Society.

Yamaguchi, Kaoru (2020), Money and Macroeconomic Dynamics-Accounting System Dynamics Approach, Edition 5, Awaji Island, Japan: Japan Futures Research Center. http://www.muratopia.org/Yamaguchi/macrodynamics/Macro\%20Dynamics.pdf adresinden alındı, Erişim Tarihi: 26.05.2021

Yunna, Wu - Kaifeng, Chen - Yisheng, Yong - Feng Tiantian (2015), “A System Dynamics Analysis Of Technology, Cost And Policy That Affect The Market Competition Of Shale Gas İn China", Renewable and Sustainable Energy Reviews, pp.235-243.

Yücel, Elif - Saraç, Mehlika - Çabuk, Adem (2012), “Accounting Education in Turkey and Professional Accountant Candidates Expectations from Accounting Education: Uludag University Application”, Business and Economics Research Journal, 3(1), pp.91-108.

Zaif, Figen - Ayanoğlu, Yıldız (2007), "Muhasebe Eğitiminde Kalitenin Artırılmasında Ders Programlarının Önemi: Türkiye'de Bir İnceleme”, Gazi Üniversitesi İktisadi ve İdari Bilimler Fakültesi Dergisi, ss.115-136. 
